\title{
History of the current understanding and management of tethered spinal cord
}

\author{
Sam Safavi-Abbasi, MD, PhD, ${ }^{1}$ Timothy B. Mapstone, MD, ${ }^{2}$ Jacob B. Archer, MD, ${ }^{2}$ \\ Christopher Wilson, MD, ${ }^{2}$ Nicholas Theodore, MD, ${ }^{1}$ Robert F. Spetzler, MD, ${ }^{1}$ and \\ Mark C. Preul, MD ${ }^{1}$
}

\begin{abstract}
1Department of Neurosurgery, Barrow Neurological Institute, St. Joseph's Hospital and Medical Center, Phoenix, Arizona; and ${ }^{2}$ Department of Neurosurgery, University of Oklahoma Health Science Center, Oklahoma City, Oklahoma
\end{abstract}

\begin{abstract}
An understanding of the underlying pathophysiology of tethered cord syndrome (TCS) and modern management strategies have only developed within the past few decades. Current understanding of this entity first began with the understanding and management of spina bifida; this later led to the gradual recognition of spina bifida occulta and the symptoms associated with tethering of the filum terminale. In the 17th century, Dutch anatomists provided the first descriptions and initiated surgical management efforts for spina bifida. In the 19th century, the term "spina bifida occulta" was coined and various presentations of spinal dysraphism were appreciated. The association of urinary, cutaneous, and skeletal abnormalities with spinal dysraphism was recognized in the 20th century. Early in the 20th century, some physicians began to suspect that traction on the conus medullaris caused myelodysplasia-related symptoms and that prophylactic surgical management could prevent the occurrence of clinical manifestations. It was not, however, until later in the 20th century that the term "tethered spinal cord" and the modern management of TCS were introduced. This gradual advancement in understanding at a time before the development of modern imaging modalities illustrates how, over the centuries, anatomists, pathologists, neurologists, and surgeons used clinical examination, a high level of suspicion, and interest in the subtle and overt clinical appearances of spinal dysraphism and TCS to advance understanding of pathophysiology, clinical appearance, and treatment of this entity. With the availability of modern imaging, spinal dysraphism can now be diagnosed and treated as early as the intrauterine stage.
\end{abstract}

http://thejns.org/doi/abs/10.3171/2015.11.SPINE15406

KEY WORDS spina bifida; tethered cord syndrome; history of neurosurgery; spinal cord; congenital

$\mathrm{T}$ HE term "tethered cord syndrome" (TCS) represents both an individual diagnosis and a combination of signs and symptoms associated with various forms of spinal dysraphism. ${ }^{48}$ Historically, the understanding of TCS was closely associated with knowledge of the underlying causes of spinal cord tethering and associated dysraphisms, including spina bifida aperta (myelomeningocele) and spina bifida occulta (lipomyelomeningocele, occult spinal dysraphism) ${ }^{3,33,47}$ A better understanding of the underlying pathophysiology and modern management strategies for these conditions only developed within the past few decades. ${ }^{3,47,48}$ Today, the unifying concept of the conditions included within TCS is the pathophysiology of increased tension and aberrant stretching of the spinal cord.

\section{7th-18th Centuries: Early Accounts and Pathological Descriptions of Spina Bifida}

Although descriptions and archeological accounts of spinal malformations resembling spina bifida date back to $10,000 \mathrm{BCE}, 16,39$ firm clinical comprehension can only be traced to the 17th century, when Dutch anatomists correctly described the entity and initiated the first surgical management efforts..$^{10,28,39,43}$ The earliest known descriptions and surgical management attempts were by Pieter van Foreest (1521-1597, also referred to as Petrus Forestus). In 1610 he described a neck mass in a 2-year-old child, which he tried to treat by ligation. ${ }^{16,28}$ However, the first formal description came from Nicolaes Tulp ${ }^{43}$ (1593-1674) (Fig. 1). 


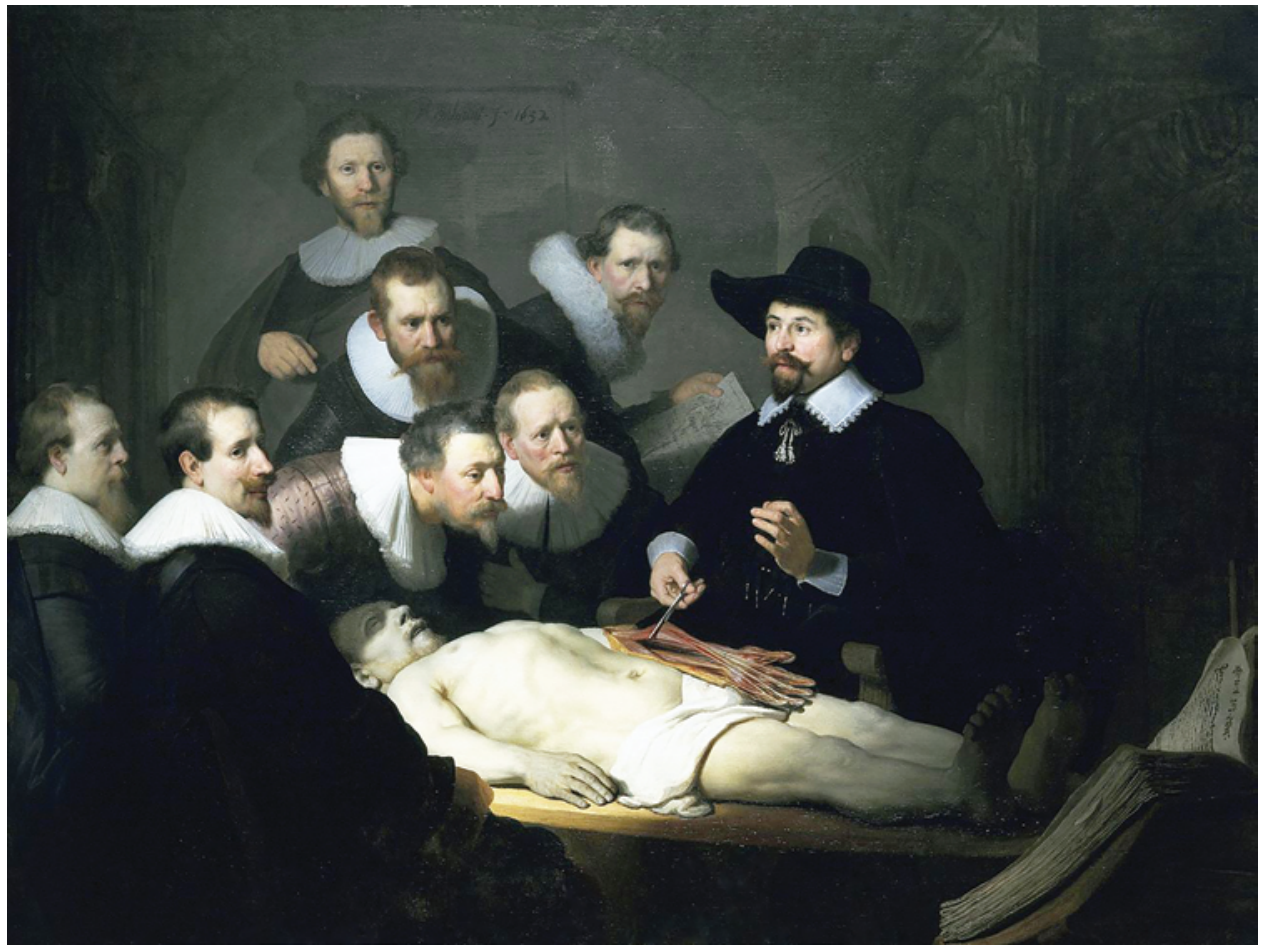

FIG. 1. Rembrandt's 1632 painting, The Anatomy Lesson of Dr. Nicolaes Tulp. Tulp was a fitting subject for Rembrandt's interest and this painting is regarded as one of Rembrandt's best. There is evidence that the actual anatomized arm used for the painting had originally belonged to Andreas Vesalius, as Rembrandt was an avid collector of curios, especially antiques and odd objects he thought might be useful for his art.9.37 Born Claes Pieterszoon, Tulp changed his name to the more formal Nicolaes and adopted the Dutch moniker "tulp" after he had hung a sign of the tulip above his door or had adopted the Dutch flower emblem. Many of his patients were probably illiterate, and the sign of the tulip probably better identified him. Not only a practicing physician, Tulp was a Praelector Anatomiae of the Amsterdam Guild of Surgeons and was involved in Amsterdam civic life; he became mayor in 1654 and served 4 terms. The painting is housed in the Mauritshuis in The Hague.

It is in Tulp's surgical textbook Observationes Medicae, ${ }^{43}$ published in 1641 , that the first documented use of the term "spina bifida" is found. He described 6 cases with anatomical abnormalities he termed spina bifida and sketched the entity (Fig. 2) ${ }^{43}$ In addition, he described 1 patient with a myelomeningocele whom he treated surgically by dissecting the myelomeningocele sac and ligating the pedicle. However, the patient died shortly after the procedure as a result of infection at the surgical site. Recognizing that surgical intervention for spinal deformity was associated with grave risks to patients, including further damage to spinal cord function, ${ }^{16}$ Tulp cautioned others to "let the surgeons not unprudently open such a swelling, but force them to see the shame this would undoubtedly bring upon themselves." 10,43

In his 1691 Observationum Anatomico-Chirurgicarum Centuria, another Dutch anatomist, botanist, and physician, Frederik Ruysch (1638-1731) (Fig. 3), described at least 10 cases of spina bifida. ${ }^{34}$ Ruysch apparently had a great deal of exposure to anatomical anomalies visible at birth, as he was chief instructor to Amsterdam's midwives (1668). Concerned about proper handling and safety of newborns, he would not allow the midwives to practice until he had personally examined them. Up until Morgagni, Ruysch, who also knew and referenced Tulp's work, was perhaps the foremost expert on the anatomical observations and clinical implications of spina bifida. His sec- tion "A Tumor in the Loins of a Foetus with a Bifid Spine," along with 2 subsequent sections of observations on spina bifida in his book, including myelomeningocele or meningocele, were frequently cited by contemporaries. ${ }^{35,36}$

Ruysch drew clear inferences that the "tumor" of the bifid spine was often associated with hydrocephalus and remarked that "it is almost the same disorder, allowing for the difference of situation (location of head versus spine)." Ruysch appears to have recognized the difference between meningocele and myelomeningocele, writing that the "tumor is in some measure soft, more especially in its middle, and frequently it is limpid, as if it was an hydatid, but sometimes it is found opace [opaque, i.e. covered with skin versus a thin membrane]." Ruysch also settled the claim that some believed the bifid spine was actually 2 parts:

But never did I observe the vertebrae so divided in this disorder as some would have us imagine, that they have totally receded in the middle from each other into two distinct parts....The vertebrae only open or recede from each other in their back part, near the spinal processes, the stronger part, that is, the body of the vertebrae remaining entire....

Ruysch did not believe that a surgical cure should be attempted for the "tumorous" mass, as "none of the infants for which I have been hitherto concerned have escaped, nor did I know one of them cured by any person...." He 


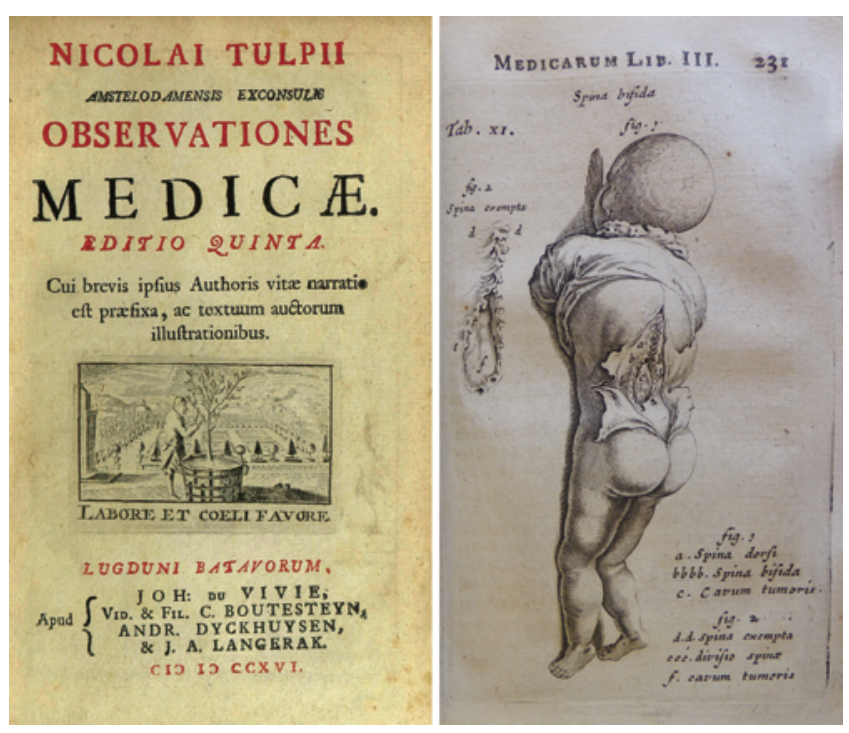

FIG. 2. Left: Title page of the 1716 edition of Tulp's Observationes Medicae. Originally published in 1641, the book went through several editions owing to its popularity over the next 100 years. Tulp wrote the book as a gift for his son, Dirck, who had just graduated from medical school at Leiden, and specifically dedicated the 1652 edition to his son after his untimely death. The title is a common title for the period, as physicians wrote books on their experiences or observations from their own practices, although none were so well constructed and educational as Tulp's. Right: Illustration of an infant's spinal bifid malformation from Observationes Medicae (1716 edition). Preoccupied with the study of anatomy, Tulp labeled various structures and provided a close-up figure of the lumbar abnormality. It appears from the sketch that the placode has not been entered or dissected ("cavum tumoris"). It has been suggested that Tulp drew many of his own sketches. Courtesy of Arizona Health Sciences Library, Special Collections, University of Arizona, Tucson, Arizona

suggested that a loose-fitting application of plaster with an astringent being changed twice daily could be a "palliative cure." However, "we observe that this tumor being opened accelerates death of the infant" and that even after a needle puncture, the infants expire in a few days." Rusych wrote excellent observations on the spinal levels associated with the occurrence of spina bifida along with the associated spinal motor dysfunction. ${ }^{35}$

Italian anatomist Giovanni Battista Morgagni (16821771) (Fig. 4), considered one of the founders of modern medicine and especially anatomical pathology, provided the first clear clinical description of the association between hydrocephalus and spina bifida in his immense 1765 work, De Sedibus et Causis Morborum per Anatomen Indagatis (Of the Seats and Causes of Diseases Investigated through Anatomy) (Fig. 5). ${ }^{29,30,39} \mathrm{He}$ described several postmortem cases of children who had been born with spina bifida and hydrocephalus. Like Ruysch, it is clear that Morgagni recognized the accumulation of cerebrospinal fluid as a pathophysiological process, describing the collection of fluid within the brain and spinal cord as "hydrops cerebri et medullaris" or "excessive fluid collection."'16 Morgagni acknowledged that, like chronic hydrocephalus and its pathological consequences, spina bifida was also the result of a pathological process, and more than any of his predecessors, he related the anatomical consequences to the pathology. In a section titled "Spina bifida," Morgagni wrote:

The chronic form of hydrocephalus is so often connected with fluid in the spinal canal, that the circumstance of their having been associated in one letter [a short report in letter form that Morgagni received but did not credit] admits of easy explanation. Fluid may, however, be deposited in one independent of the other, and may happen in adults as well as in foetuses and children. It occurs, indeed, with the greatest facility in foetuses, because in them the bones of the vertebrae readily yield, like the bones of the cranium. At one time some of the vertebrae are bifid; and at others, all of them. By the fluid pressing against the membranes of the medulla spinalis, a tumour is formed upon the posterior surface, proportionate to the quantity of water, as in hydrocephalus. The vertebrae are chiefly deficient in the situation of the spinous processes, not only because the bones are naturally disjoined in that part, but more particularly, in my opinion, because there is less resistance there than laterally, where the muscles and tendons are situated. Ruysch was surprised that this tumour did not more frequently protrude at the inferior and outer part of the os sacrum, where there is naturally an opening. ${ }^{30}$

Morgagni made prescient comments on the pathological and anatomical relationships of the bifid bones, hydrocephalus, the relationships of the placode and nerves, and the potential for detriment to the patient without exact knowledge of the pathological processes. In the same section, Morgagni made observations on what may be chronic inflammatory evidence associated with spina bifida, or even situations of tethered cord or nerve roots. He believed "that we must not always expect a hydrocephalus to exist in the same patient in whom there is a hydro-rachitis."10 Morgagni wrote that:

There is naturally a little fluid in the spinal canal, and should this exceed the natural quantity, it may be considered as an occasion of hydrorachitis. The spine has been bifid in the neck and back at the same time.... It has already been observed that the cauda equina does not descend to the os coccygis, which circumstance will probably explain the reason of the greater protraction of life, which Ruysch observed, when the tumour was seated on this part. In such cases so many nerves are not protruded or injured, as in other cases; in consequence of which there is less probability of paralysis of the lower limbs, of the sphincter ani, and of the bladder, which in them is likely to happen. ${ }^{30}$

In what may be the first description of instructions on how to manage a myelomeningocele surgically, Morgagni showed his concern for the welfare of the neonate with such a spinal problem and directed that the child be managed correctly and with insight as to the pathological process. His writing demonstrates an especially gentle approach:

The life of the little patient, however, is usually cut short by convulsions and other consequences of injury to the nerves; and these evils happen more speedily, if the nerves are pricked in opening the tumour, or if they are exposed to the contact of air. In the following instance the tumour of spina bifida was rashly opened. A boy was brought to me having a tumour on the lumbar vertebrae, which was soft, and in many places translucent: at birth it was small, but within ten months it had grown to the size of a fist; the boy was strong, and was well formed, even in his lower limbs, although they were weak. I cautioned the parents not to have the tumour opened. A surgeon, however, who being ignorant of its nature 

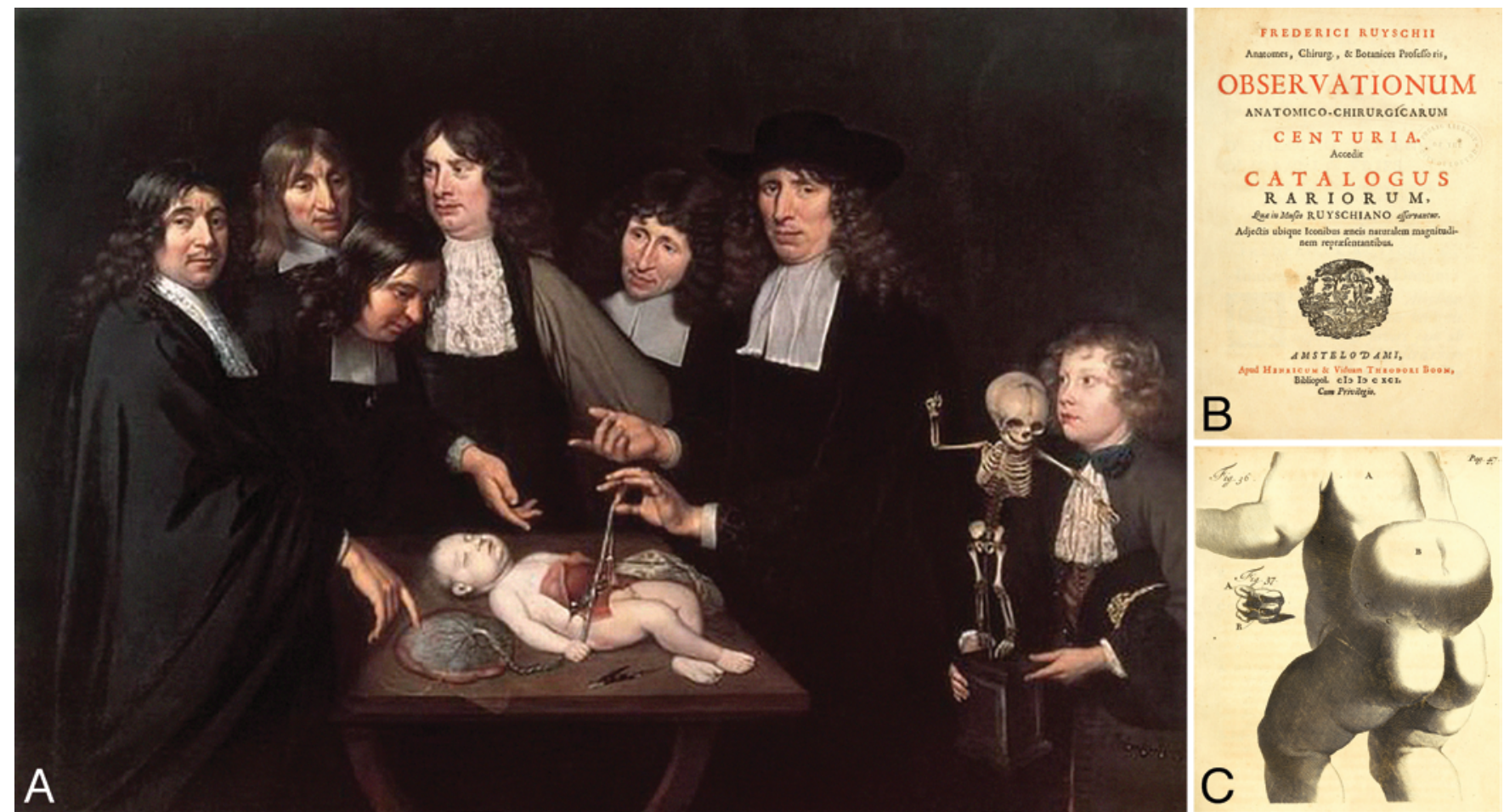

FIG. 3. A: In Jan van Neck's painting, The Anatomy Lesson of Dr. Frederik Ruysch, Ruysch is teaching a dissection of a newborn baby, still connected to its placenta. He is best remembered as a botanist and and was one of the great anatomists of his time, having been the pupil of Franciscus Sylvius (1614-1672) at Leiden. Ruysch pioneered cadaver tissue preparation using arterial embalming solutions and created popular "anatomical dioramas" and curiosities, many of which he sold off to Peter the Great during his visit to Amsterdam. Like Tulp, Ruysch was an anatomy praelector of the Amsterdam's surgeon's guild, and because of his extensive knowledge of biological processes and preservation of tissues, he served as a forensic advisor to the Amsterdam courts. B: Title page of Ruysch's Observationum anatomico-chirurgicarum centuria (1691), which contained the best contemporary description of spina bifida and myelomeningocele, including its management. C: Ruysch's image of an 8-month-old infant 14 days after death. From the descriptive legend this is likely a myelomeningocele. Also shown are 3 bifid lumbar vertebrae. Images in panels $B$ and $C$ are photographs from Dr. Preul's collection.

confidently promised to cure the disease, was permitted to thrust a knife into the middle of the tumour, from which, at first, a considerable quantity of limpid fluid, and, towards the last, some bloody fluid escaped; he afterwards introduced a tent into the orifice. The child did not cease to cry; the body trembled; the face became pale and wrinkled, and death followed on the third day. ${ }^{30}$

The first physician to clearly hypothesize that spina bifida was the result of a developmental anomaly based on anatomical, pathological, and clinical evidence was the French anatomist and pathologist, Jean Cruveilhier (1791-1874) (Fig. 6). Cruveilhier was in the vanguard of the developing French pathoanatomical-clinical, evidence-based tradition that would later fully develop at $\mathrm{La}$ Salpêtrière under Jean-Martin Charcot (1825-1893). Inspired by Xavier Bichat (1771-1802) and René Laennec (1781-1826), Cruveilhier wrote his 1816 thesis, On the pathological anatomy in general and the transformations of organic productions in particular, in which he promoted methodology based on correlating clinical background with pathological anatomical causes. After a few years of practice outside Paris, Cruveilhier was promoted to professor of descriptive anatomy in Paris and was named chief of surgery at La Salpêtrière and chief of pathological anatomy, with critical support for this promotion coming from Guillaume Dupuytren (1777-1835). ${ }^{6}$
The development of the pathoanatomical-clinical, evidence-based method fostered the diversity of neurological symptoms to be gathered into specific nosological syndromes. Cruveilhier contributed to identification and description of neurological and neurosurgical diseases, including congenital central nervous system malformations (hydrocephalus, spina bifida, and craniosynostosis). ${ }^{12} \mathrm{Cru}-$ veilhier described what is now known as Arnold-Chiari Type II malformation in association with spina bifida. Like Morgagni, he recognized and elaborated upon the mortality related to opening of the myelomeningocele sac. ${ }^{1}$

Within the environment of the progressive French medical system, which had begun to promote rich neurological debates, Jean Cruveilhier published his treatise on pathological anatomy, Anatomie pathologique du corps humain, ou descriptions, avec figures lithographiées et coloriées, des altérations morbides dont le corps humain est susceptible, in Paris between 1829 and 1842.11 Cruveilhier reemphasized the tradition of Morgagni, but broke new ground with detailed, colored, informative lithographic illustrations of the pathological conditions of the human body at a time when the majority of anatomical works were text-based, nonillustrated works still based on normal anatomy. Cruveilhier combined thorough clinical knowledge with sustained, masterful anatomical and case 


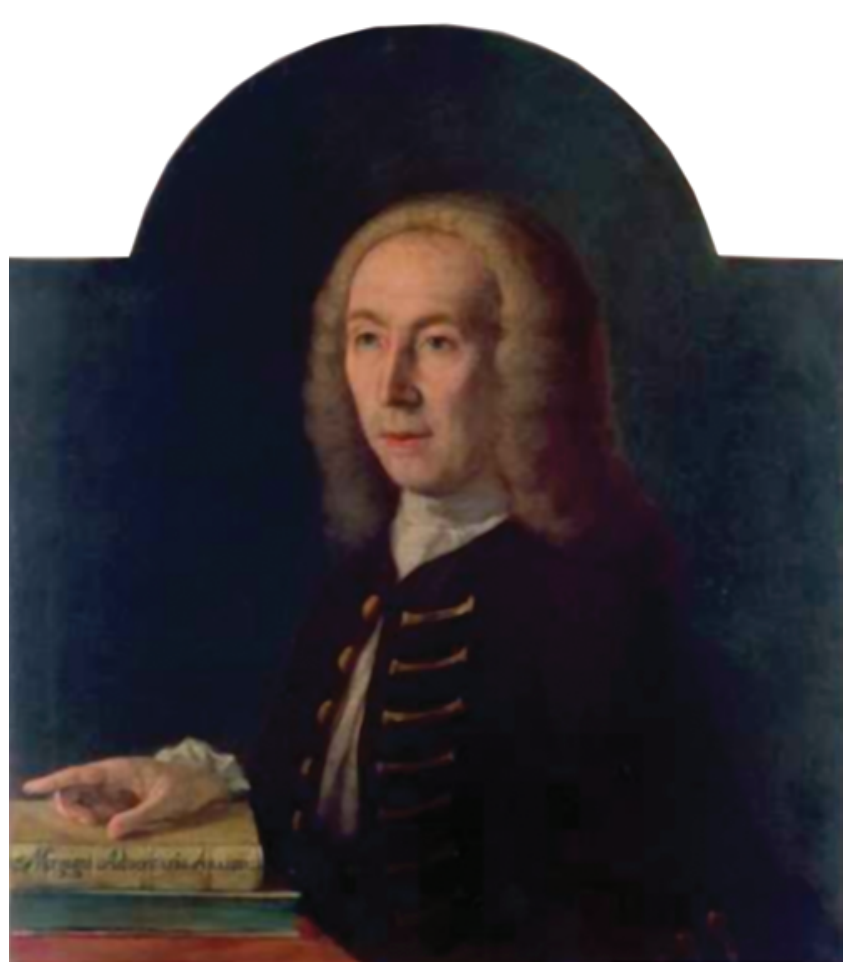

FIG. 4. The last of 3 oil-on-canvas portraits of Giovanni Battista Morgagni by Italian painter Antonio Belloni (c. 1720-1790) showing Morgagni with his hand on a copy of his Adversaria Anatomica, painted May 9 , 1751 , in Morgagni's house. The paintings belong to the Pinacoteca Civica of Forli and are displayed in a room of the public library of Palazzo del Merenda, former site of the old hospital, Ospedale della Casa di Dio per gli Infermi. Photographs of paintings are from Dr. Preul's collection.

dissections. Many of the illustrations were drawings of his own patients, whom he had followed over time; he was thus able to report precisely their clinical symptomatology with their autopsies. His illustrations also make note of a concept of "arachnitis spinale," which may indicate that Cruveilhier suspected that other processes (later to be associated with TCS) were involved in myelomeningocele.

\section{9th Century: Establishment of Pathological Understanding and Early Anecdotal Surgical Reports}

The German pathologist, Rudolf Virchow (1821-1902), first coined the term "spina bifida occulta," which is still used today. Virchow contributed additional insight into the developmental aberrations that lead to the development of spinal dysraphism. ${ }^{44}$ His work marked the beginning of exploration into the pathological associations between TCS and spinal dysraphism. His pupil, Friedrich Daniel von Recklinghausen (1833-1910), later gave an extensive description of various presentations of spinal dysraphism and recognized that spina bifida occulta could be associated with lumbosacral hypertrichosis. ${ }^{45}$ In an autopsy report, von Recklinghausen described tethering and traction of the cord: "The lower end of the spinal cord, the conus medullaris, was not at the level of the second lumbar vertebra as usual, but that of the second sacral vertebra." ${ }^{45} \mathrm{He}$ further recognized what appears to be a lumbosacral lipo-

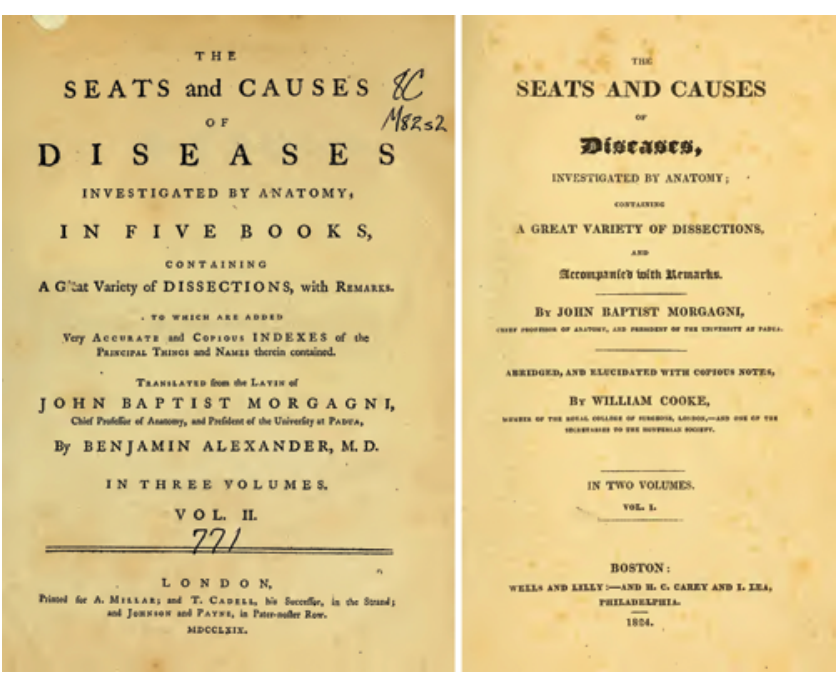

FIG. 5. Left: Title page from the 1769 London edition of the 3-volume complete English translation of Morgagni's De Sedibus et Causis Morborum per Anatomem Indagatis (1796). Morgagni was nearly 80 when the work was published, having worked on it for 20 years. Right: The work was amazingly popular and influential well into the 19th century as evidenced by the 1824 abridged English edition. Morgagni related that his work was motivated by conversations with a young friend who persuaded him to describe his experiences and observations. The original construct was a series of 70 letters collated into a systematic 5-section 2-volume treatise published in Venice. Morgagni's comments on spina bifida are contained in the first volume. Although not free of error, verbosity, or overstatement, Morgagni's work did for pathological anatomy what Vesalius had done 2 centuries earlier for normal anatomy. Over his whole career, Morgagni treated pathological anatomy as a science, demanding objectivity and precision. Images are photographs from Dr. Preul's collection.

myelomeningocele: "The aforementioned fat substance seemed to be an unusually developed extradural cushion of fat which often accompanies nerve fibres from the dural sac to the vertebral foramens, however, in areas where the dura was cut the cushion of fat extended abnormally in [the] intradural direction, penetrated the soft meninx of the spinal cord...."45

Early surgical attempts to correct spina bifida were associated with high mortality. It was not until the advent of aseptic surgical procedures and improved surgical technique in the late 19th and early 20th centuries that successful surgical closures of spina bifida were possible or acceptable. ${ }^{10,17,18,31,32,34,38,46}$ As early as 1857, Athol Johnson at the Hospital for Sick Children in Toronto presented what appears to be the first surgical management of a lipomyelomeningocele. He reported a case of a child with an ulcer over the sacrum adjacent to a "small pendulous excrescence of fat covered with integument." 21 The patient developed twitching in the right lower extremity, which prompted his parents to seek surgical management of his condition. At 10 months of age the patient underwent an operation performed by Johnson who noted that "...the fatty tumor was found to be adherent to the parts beneath, requiring careful dissection, as it protruded through an aperture large enough to admit the end of the finger, in the posterior wall of the sacral canal." ${ }^{21}$ His operative report indicated that the fatty tumor was fixed within the spinal canal and he observed that "...the tumour is remarkable as 


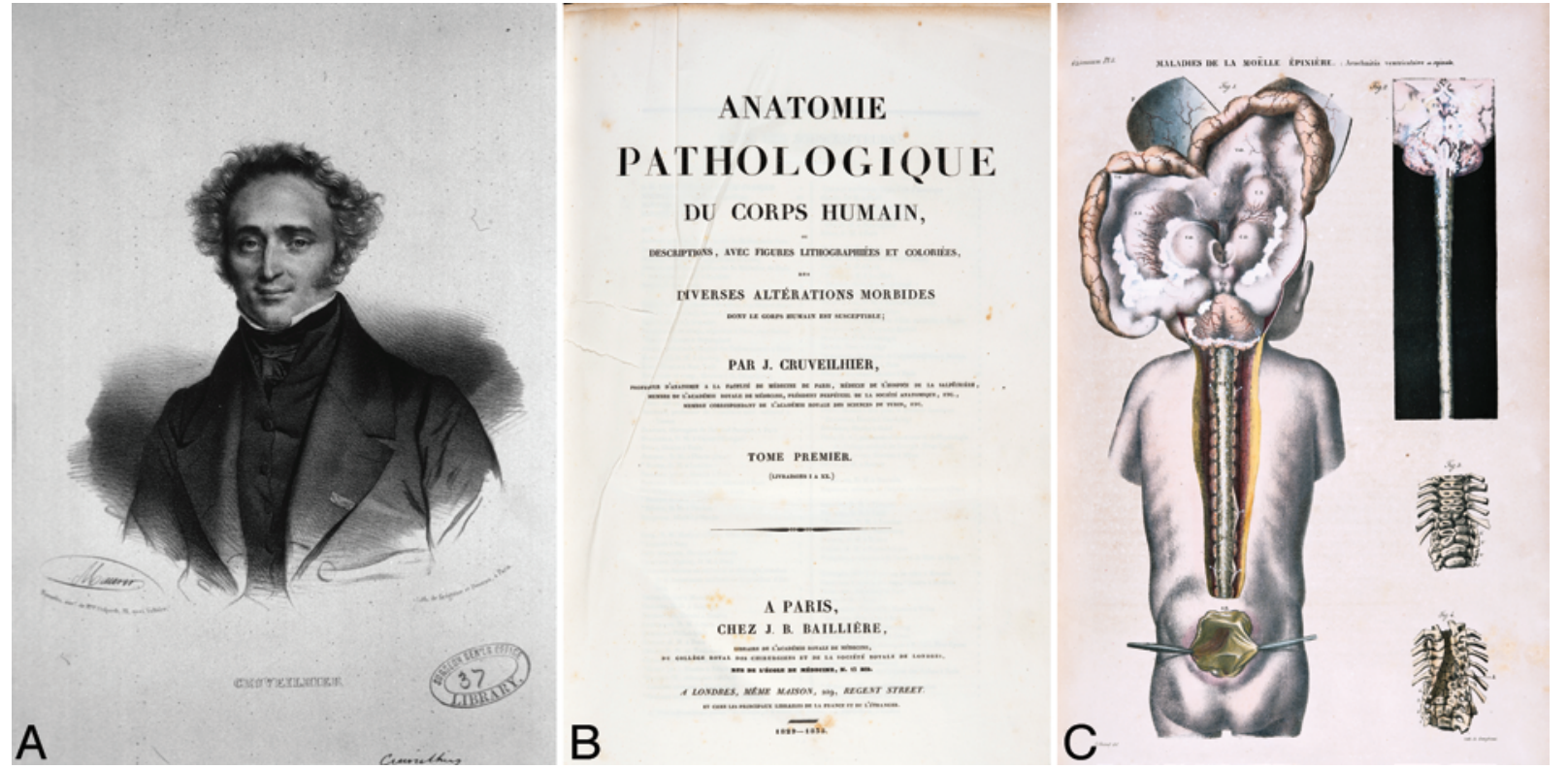

FIG. 6. A: Jean Cruveilhier as a young physician, anatomist, and pathologist. Photograph courtesy of the National Library of Medicine, History of Medicine Division. B: Title page from Cruveilhier's work, which showed remarkable color illustrations such as a myelomeningocele. C: The spinal cord and brain are fully dissected and reveal evidence of hydrocephalus; side panels demonstrate bifid abnormal vertebral anatomy and what appears to be arachnoid inflammation or "arachnitis." Images in panels B and C are courtesy of The Huntington Library, Art Collections, and Botanical Gardens, San Marino, California.

respects its situation in the interior of the spinal canal, and the co-existence of a deficiency of the laminae allowing the tumour to make its way externally." 21 The child was reported to have done well postoperatively with cessation of involuntary convulsive movements in the right lower extremity and was discharged home. Johnson found that the patient "was able to stand, and was beginning to walk a little." ${ }^{21}$ However, 6 weeks after returning home the child developed peritonitis and died. ${ }^{21}$ In 1867, T. Holmes, also a surgeon at the Hospital for Sick Children, provided a comprehensive review of the literature on congenital sacral tumors, citing Johnson's paper: "I assisted Mr. Johnson at the operation. The tumor protruded from the spinal canal through a congenital cleft in the sacrum." 19

The early surgical and clinical work of W. L. Jones is similar. In 1891, he described what appears to be the typical clinical symptoms associated with TCS in a 22-yearold male who developed talipes equinovarus deformities, weakness and atrophy of the lower extremities, urinary symptoms, and burning pain in his feet. ${ }^{23}$ Based on his clinical observation and physical examination, Jones decided that the patient suffered from spina bifida occulta and detailed his operative management:

The parts selected for operation were shaved and thoroughly washed with perchloride solution, and a quadrilateral skin flap, with its base to the left side, reflected... after separating and holding aside the spinal muscles, sufficient of the first sacral vertebra was removed to expose the cauda equine. A dense adventitious fibrous band now came into view, stretching across the spinal canal and compressing the cauda equina. ${ }^{23}$

After surgical division of the fibrous band, the patient's symptoms improved significantly, with the patient regaining the ability to walk and function. ${ }^{3}$
Although their accounts are anecdotal, the cases reported by Johnson and Jones are noteworthy pioneering attempts at surgical exploration and management of spinal dysraphism. However, for almost another century the surgical management of lipomyelomeningocele, as recounted by Johnson, ${ }^{21}$ and that of TCS, as described by Jones, ${ }^{23}$ was regarded as experimental.

\section{Early and Mid-20th Century: Recognition of Signs and Symptoms, Understanding of Pathology, First Imaging and Surgical Series}

The association of urinary, cutaneous, orthopedic, and skeletal abnormalities with occult spinal dysraphism was recognized in the early 20th century. Spinal defects in patients with cutaneous stigmata such as hypertrichosis or asymmetry of the anal cleft began to be recognized on "Roentgen rays." ",40 In 1909, Austrian neurologist Alfred Fuchs described "anomalies of development, and enuresis nocturna associated often with spina bifida occulta" and coined the term "myelodysplasia."14 In 1916, American neurologist William G. Spiller, aware of Fuchs' work, extensively reviewed several papers ${ }^{40}$ written on the subject and concluded that "enuresis of older children and adults, may not necessarily be merely nocturnal, may occasionally be [a] sign of spina bifida occulta...."

Spiller described 2 young male patients with myelodysplasia, whose urinary and motor symptoms worsened with strenuous exercise and extensive flexion of the spine secondary to training for rowing. ${ }^{40} \mathrm{He}$ hypothesized that enuresis may occur from "stretching the cauda equina." This was a completely new understanding of a dynamic component to the progression of symptoms related to stretching of the cord and resulted in an impetus for early 
identification of patients with myelodysplastic signs and symptoms.

In 1918, American surgeon Walter Brickner recognized the association of spina bifida occulta with scoliosis and reported his surgical series of laminectomy and resection of lipomyelomeningoceles. ${ }^{7}$ He proposed that early prophylactic surgical intervention to treat patients with spina bifida occulta might be useful in the prevention of progressive neurological deterioration. ${ }^{3,7} \mathrm{He}$ concluded that surgery is indicated "in infants and children, with spina bifida occulta with congenital lipoma or hypertrichosis even though without any symptoms."

Thus, some physicians started to suspect in the early 20th century that traction of the conus medullaris even in the absence of a lipomyelomeningocele or tumor might cause myelodysplasia-related symptoms and that prophylactic surgical management might prevent occurrence of clinical symptoms. Ben Lichtenstein (Fig. 7), a neuropathologist from the Department of Neurology and Neurological Surgery at the University of Illinois in Chicago, wrote in his detailed manuscript entitled Spinal Dysraphism, read at the meeting of the Chicago Neurological Society in 1940, that "It is in cases in which the dysraphic state is manifested solely in the spinal cord that I am particularly interested, as the absence of clinical and roentgenographic evidence of a vertebral defect may lead the clinician to exclude the possibility of such a disorder of the spinal cord...." 27

Intuitively, Lichtenstein observed that neural forms of dysplasia might be present without cutaneous or mesodermal defects. ${ }^{27}$ Two years later, in 1942, he further indicated that fixation of the spinal cord at an abnormally low level could cause a low position of the conus medullaris and abnormal stretching of the spinal cord at the site of fixation. ${ }^{26}$ His work provided the basis for understanding TCS as a separate diagnosis existing without other apparent signs of spinal dysraphism. Although other physicians observed and believed that myelodysplasia might be present without cutaneous or bony abnormalities, ${ }^{22,27}$ Lichenstein's work was not widely accepted. ${ }^{48}$ However, the American orthopedic surgeon George Garceau (Fig. 8) from Indiana University was familiar with the work of Lichtenstein, and in 1952 at the Joint Meeting of the Orthopedic Association in London, Garceau used the phrase "cord-traction syndrome." In 1953, he published an article, "The Filum Terminale Syndrome" to describe orthopedic spinal deformities, in particular scoliosis and progressive neurological deterioration, due to a thickened filum terminale. ${ }^{15}$ He described 3 patients who had recovered after surgical sectioning of the filum terminale. ${ }^{8}$ In the case of a 13 -year-old boy with tingling, weakness, and stiffness in the right leg he wrote that

\begin{abstract}
.... laminectomy was performed.... A thick, tough and tight filum terminale was found. Stimulation of the filum gave no response; the filum was therefore resected. Microscopic examination of the specimen revealed a fibrous-tissue band with a few scattered nerve fibers....the question of the role of the tight filum terminale as a cause of idiopathic scoliosis is suggested but remains unanswered..$^{15}$
\end{abstract}

In 1956, neurosurgeons Peter Jones and Grafton Love provided a more detailed review of embryologic, pathologic, and surgical findings in 6 patients. In each case, symptomatic improvement was obtained after intradural lum-

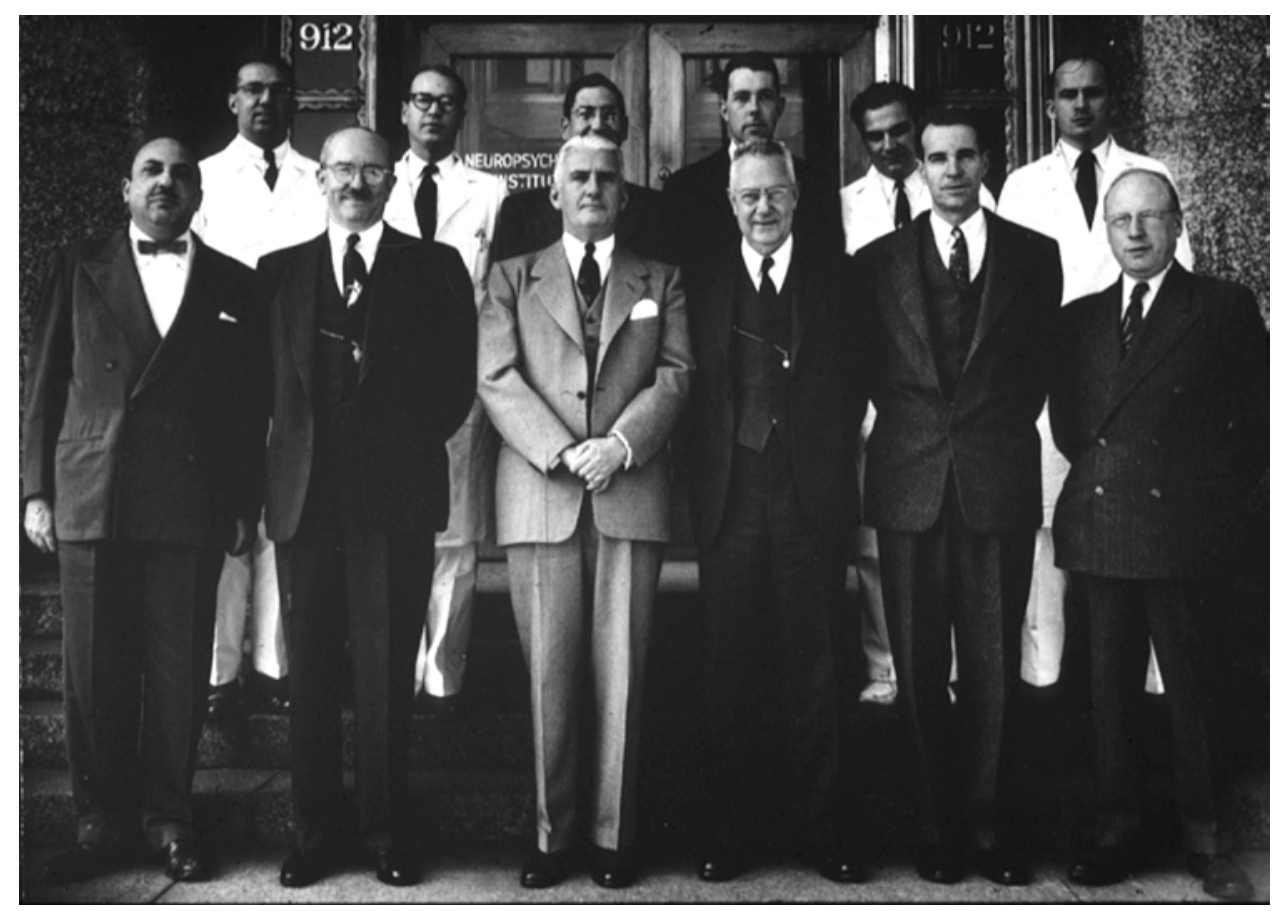

FIG. 7. The Faculty of the Department of Neurology and Neurological Surgery at the University of Illinois in Chicago, 1954. From the left, front row, Ben Lichtenstein, Roland P. Mackay, Eric Oldberg, Percival Bailey, Fred Gibbs, Paul Bucy; back row, third from left, Oscar Sugar, third from right, John Garvin; each is flanked by residents and fellows. Lichtenstein, a neuropathologist, suspected that neural forms of dysplasia might be present without cutaneous or mesodermal defect. Used with permission from the University of Illinois at Chicago College of Medicine, Center for the History of Neurosciences. 
bosacral exploration and resection of the filum terminale. ${ }^{22}$ These authors also noted that "myelography is of great value in determining the exact etiological factors of disability."22 In the 1960s, many neurosurgeons recognized clinical symptoms including enuresis, foot deformities, scoliosis, progressive neurological symptoms due to various causes, and other presentations of occult spinal dysraphism, and several surgical series with satisfying results were published. ${ }^{25,49}$ Thus, increasingly, clinicians began to differentiate between the various causes of TCS, and many emphasized the progressive deterioration in function while stressing the value of prophylactic surgery. ${ }^{5,18}$

In 1975, pediatric neurosurgeon Frank Anderson published a series of 75 patients with occult spinal dysraphism and TCS, in which excellent surgical results and improvement of pain had been achieved. ${ }^{4}$ Controversy nevertheless persisted and some surgeons still believed repair of spinal dysraphic conditions such as lipomyelomeningocele consisted only of cosmetic repair. ${ }^{18}$ At the 1987 meeting of the American Association of Neurological Surgeons, David McLone and Thomas Naidich still debated whether TCS was "fact or fiction."

\section{Modern Era: Improved Imaging, Diagnosis, Understanding of Pathophysiology and Embryology, and Establishment of Standards of Care}

The efforts and leadership of 3 pediatric neurosurgeons (known as the "3 Hs") from the Hospital for Sick Children in Toronto (Fig. 9) substantiated that TCS is a clinical and surgical entity and broadened our recent understanding of the disease. ${ }^{20}$ Publications by Harold Hoffman, Bruce Hendrick, and Robin Humphreys represent some of the most important modern series on TCS. ${ }^{17,18,20}$ Introducing the term "tethered spinal cord" to define a radiographic diagnosis of thickened filum terminale measuring $2 \mathrm{~mm}$ or more in diameter and a low-positioned conus medullaris, they wrote "We remained skeptical about the existence of the 'filum terminale syndrome' until we were introduced to the technique of supine myelography with Pantopaque. In the past 5 years with this technique, we have identified and treated 31 children for what we have termed a tethered spinal cord."'17 Furthermore, they specifically excluded many other pathological causes of TCS such as lipomyelomeningoceles; meningoceles; myelomeningocele; diastematomyelia; and intraspinal space-occupying dysraphic conditions, such as dermoid tumors, intraspinal meningoceles, neurenteric cysts, and teratomatous cysts. Their work showed that a tethered spinal cord caused by a tight filum terminale could constitute a separate diagnosis without gross pathological abnormality. Shokei Yamada and colleagues later expanded the definition of TCS by linking it to symptoms of an impairment of oxidative metabolism. In an elegant experimental and clinical study using dual wavelength reflection spectrophotometry, they demonstrated electrophysiological and metabolic deficiency in experimental and human TCS. ${ }^{47,48}$ In a series of 96 patients with lipomyelomeningocele, Hoffman et al. showed that without surgical intervention such patients develop progressive neurological dysfunction and wrote that

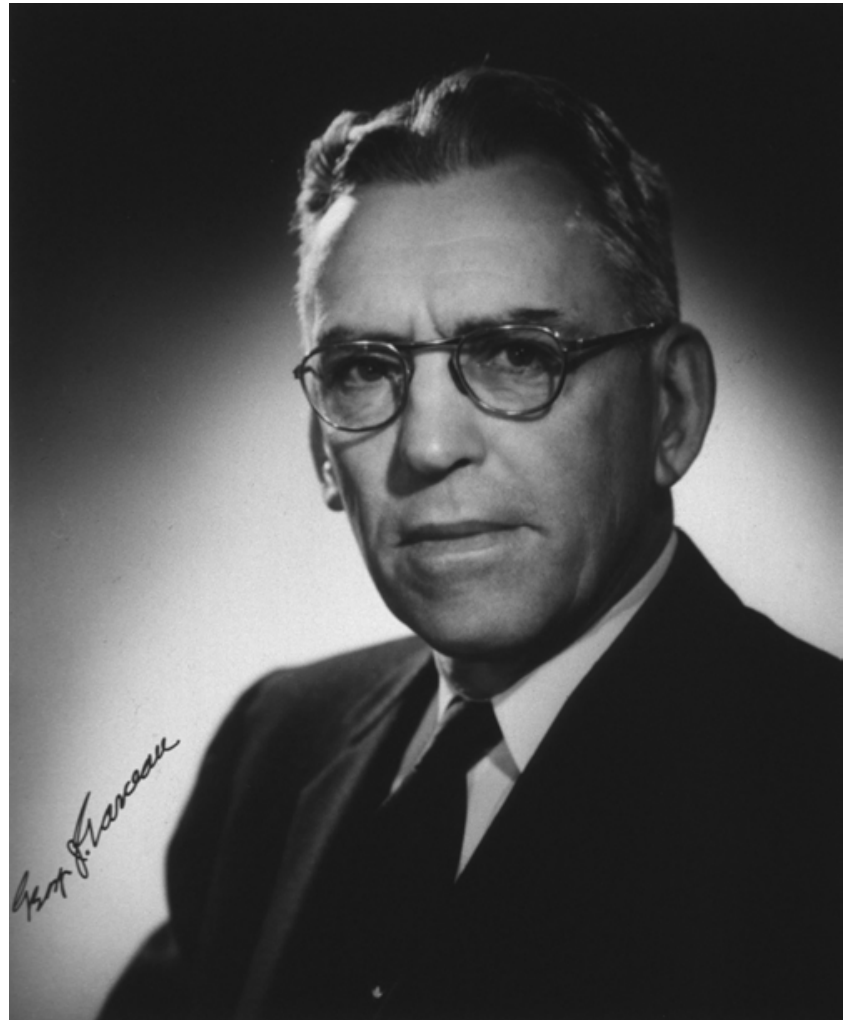

FIG. 8. The American orthopedic surgeon George Garceau who, in 1952, used the phrase "cord-traction syndrome" and published his article, "The filum terminale syndrome," to describe orthopedic spinal deformities, scoliosis, and progressive neurological deterioration due to a thickened filum terminale. Photograph courtesy of the National Library of Medicine, History of Medicine Division.

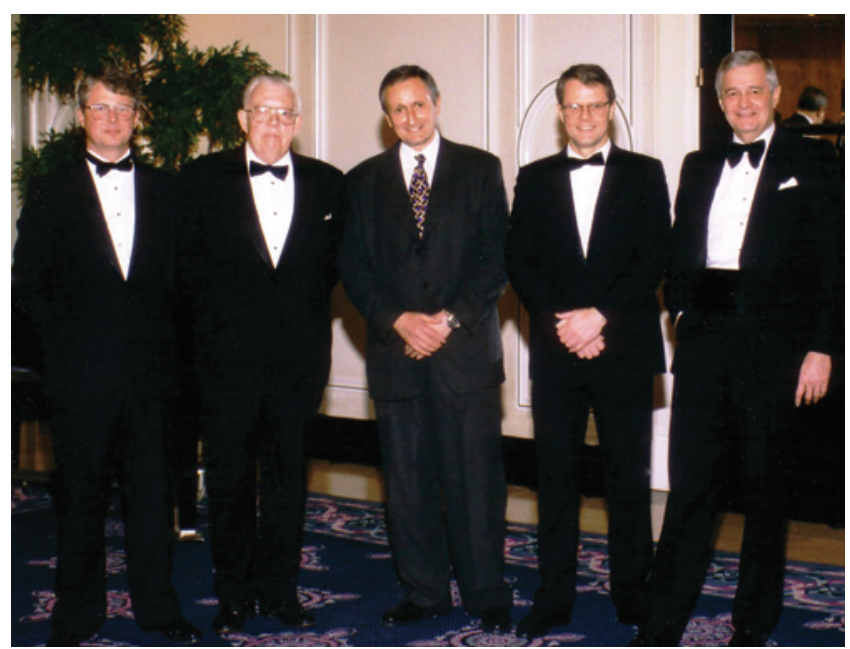

FIG. 9. Prominent neurosurgeons at the Hospital for Sick Children in Toronto: the "3 Hs"-E. Bruce Hendrick, Harold Hoffman (second and third from left), and Robin Humphreys (far right)-and their successors, James Drake (left) and James Rutka (second from right). Photograph used with permission from the University of Toronto, Division of Neurosurgery. 
"The aim of therapy, therefore, is not only the cosmetic repair of the lump on the infant's back, but the prevention of neurological deterioration.....although the fatty lump can act as a compressing mass, one should not regard these lesions as tumors and the aim of therapy should be to untether the spinal cord...."18

With improved imaging (e.g., MRI and significantly improved noninvasive imaging methods) neurosurgeons can now more readily diagnose TCS based on clinical and radiographic findings., 3,83 MRI and ultrastructural light and electron microscopy studies have shown that decreased elastic properties of the filum may exist in patients with TCS. ${ }^{13,33}$ Technological advancements within the past few decades have allowed prenatal diagnosis of spina bifida and prenatal repair of myelomeningocele to become possible. ${ }^{2}$ Although there has been progressive insight into the various causes of TCS within the past century, with clinical and pathological properties becoming better understood, there is a lack of Class I data about surgical outcomes with resulting controversy and disagreement. ${ }^{8,41}$ The challenge today still lies in correctly identifying patients who have TCS, patients who are at risk for TCS and future neurological deterioration, and those who would benefit from surgical management.

A recent survey at the 2004 meeting of the American Association of Neurological Surgeons/Congress of Neurological Surgeons (AANS/CNS) Joint Section on Pediatric Neurosurgery indicated that controversy persists, ${ }^{32}$ especially in the management of children with no radiographic abnormalities, i.e., those without a low-lying conus medullaris and with a normal-appearing filum, but who have urinary symptoms (recently called occult TCS) ${ }^{24,41,42}$ It has been suggested that the relative safety of operative management "should not be a reason to arbitrarily advise surgery in patients with normal studies and symptoms of uncertain origin." ${ }^{41}$ Randomized clinical trials may better define the associations between relatively normal-appearing imaging and those patients with obvious or subtle signs and symptoms of TCS..$^{42}$ Nevertheless, the historical path can now be followed from Nicolaes Tulp's advice against surgical management of spina bifida to modern prenatal diagnosis and management. Such progress has been paralleled by improved understanding of occult spinal dysraphism and the recognition and surgical management of TCS.

\section{Conclusions}

The historical path to the current understanding of TCS was initially closely linked to the anatomical recognition, understanding, and management of spina bifida, which then led to the proposed entity of spina bifida occulta, and then to the symptoms associated with tethering of the filum terminale and its management. Anatomical luminaries including Tulp and Ruysch suspected that the implications of spina bifida and myelomeningocele were complex, and Morgagni and Cruveilhier demonstrated additional pathological processes that they termed "arachnitis." Modern medical imaging techniques have permitted identification of the subtle and overt clinical appearances of spinal dysraphism and TCS and assessment of the evolution of its pathophysiology. With the availability of modern imaging, spinal dysraphism can now be diagnosed and treated as early as the intrauterine stage.

\section{References}

1. Adams EW: Founders of modern medicine.-II. Giovanni Battista Morgagni. Med Library Hist J:270-277, 1903

2. Adzick NS, Thom EA, Spong CY, Brock JW III, Burrows PK, Johnson MP, et al: A randomized trial of prenatal versus postnatal repair of myelomeningocele. N Engl J Med 364:993-1004, 2011

3. Agarwalla PK, Dunn IF, Scott RM, Smith ER: Tethered cord syndrome. Neurosurg Clin N Am 18:531-547, 2007

4. Anderson FM: Occult spinal dysraphism: a series of 73 cases. Pediatrics 55:826-835, 1975

5. Bassett RC: The neurologic deficit associated with lipomas of the cauda equina. Ann Surg 131:109-116, 1950

6. Berhouma M, Dubourg J, Messerer M: Cruveilhier's legacy to skull base surgery: premise of an evidence-based neuropathology in the 19th century. Clin Neurol Neurosurg 115:702-707, 2013

7. Brickner W: Spina bi fi da occulta: (1) with external signs, with symptoms; (2) with external signs, with- out symptoms; (3) without external signs, with symptoms; (4) without external signs; without symptoms. Am J Med Sci 155:473-502, 1918

8. Bui CJ, Tubbs RS, Oakes WJ: Tethered cord syndrome in children: a review. Neurosurg Focus 23(2):E2, 2007

9. Cavalcanti DD, Feindel W, Goodrich JT, Dagi TF, Prestigiacomo CJ, Preul MC: Anatomy, technology, art, and culture: toward a realistic perspective of the brain. Neurosurg Focus 27(3):E2, 2009

10. Cohen-Gadol AA, Nahed BV, Voorhees JR, Maher CO, Spencer DD: Cushing's experience with the surgical treatment of spinal dysraphism. J Neurosurg 102 (4 Suppl):441-444, 2005

11. Cruveilhier J: Anatomie pathologique du corps humain; ou, Descriptions, avec figures lithographiées et coloriées, des diverses altérations morbides dont le corps humain est susceptible. Paris: Chez J.B. Baillière, 1829

12. Flamm ES: The neurology of Jean Cruveilhier. Med Hist 17:343-355, 1973

13. Fontes RB, Saad F, Soares MS, de Oliveira F, Pinto FC, Liberti EA: Ultrastructural study of the filum terminale and its elastic fibers. Neurosurgery 58:978-984, 2006

14. Fuchs A: Ueber den klinischen Nachweis kongenitaler Defectbildungen in den unteren Ruckenmarksabschnitten (Myelodysplasie). Wien Med Wochenschr 59:2141, 1909

15. Garceau GJ: The filum terminale syndrome (the cord-traction syndrome). J Bone Joint Surg Am 35-A:711-716, 1953

16. Goodrich JT: A historical review of the surgical treatment of spina bifida, in Özek MM, Cinall G, Maixner WJ (eds): The Spina Bifida. Management and Outcome. Milan: Springer, 2008, pp 3-17

17. Hoffman HJ, Hendrick EB, Humphreys RP: The tethered spinal cord: its protean manifestations, diagnosis and surgical correction. Childs Brain 2:145-155, 1976

18. Hoffman HJ, Taecholarn C, Hendrick EB, Humphreys RP: Management of lipomyelomeningoceles. Experience at the Hospital for Sick Children, Toronto. J Neurosurg 62:1-8, 1985

19. Holmes T: On congenital sacral tumour: especially with reference to its operative treatment. BMJ 1:349-352, 1867

20. Jea A, Al-Otibi M, Rutka JT, Drake JM, Dirks PB, Kulkarni $\mathrm{AV}$, et al: The history of neurosurgery at the Hospital for Sick Children in Toronto. Neurosurgery 61:612-625, 2007

21. Johnson A: Fatty tumor from the sacrum of a child connected with the spinal membranes. Trans Pathol Soc London 8:16-18, 1857 
22. Jones PH, Love JG: Tight filum terminale. AMA Arch Surg 73:556-566, 1956

23. Jones W: Spina bifida occulta: no paralytic symptoms until seventeen years of age: spine trephined to relieve pressure on the cauda equina: recovery. BMJ 1:173-174, 1891

24. Khoury AE, Hendrick EB, McLorie GA, Kulkarni A, Churchill BM: Occult spinal dysraphism: clinical and urodynamic outcome after division of the filum terminale. J Urol 144:426-429, 443-424, 1990

25. Lassman LP, James CC: Lumbosacral lipomas: critical survey of 26 cases submitted to laminectomy. J Neurol Neurosurg Psychiatry 30:174-181, 1967

26. Lichtenstein BW: Distant neuroanatomic complications of spina bifida (spinal dysraphism) hydrocephalus, Arnold-Chiari deformity, stenosis of the aqueduct of Sylvius, etc.; pathogenesis and pathology. AMA Arch Neurol 47:195-214, 1942

27. Lichtenstein BW: Spina dysraphism: spina bifida and myelodysplasia. Arch Neurol Psychiatry 44:792-809, 1940

28. McClugage SG, Watanabe K, Shoja MM, Loukas M, Tubbs RS, Oakes WJ: The history of the surgical repair of spina bifida. Childs Nerv Syst 28:1693-1700, 2012

29. Morgagni JB: De Sedibus, et Causis Morborum per Anatomen Indagatis. Libri Quinque. Padua: Sumptibus Remondinianis, 1765

30. Morgagni JB: The Seats and Causes of Diseases Investigated by Anatomy, Containing a Great Variety of Dissections and Accompanied With Remarks. Abridged, and Elucidated With Copious Notes, by William Cooke. Boston: Wells and Lilly, 1824, Vol 1

31. Morton J: Case of spina bifida cured by injection. BMJ 1:632-633, 1872

32. Morton J: The treatment of spina bifida. BMJ 2:608-609, 1875

33. Nakanishi K, Tanaka N, Kamei N, Nakamae T, Izumi B, Ohta R, et al: Use of prone position magnetic resonance imaging for detecting the terminal filum in patients with occult tethered cord syndrome. J Neurosurg Spine 18:76-84, 2013

34. Pendleton C, Ahn ES, Jallo GI, Quiñones-Hinojosa A: Harvey Cushing and early spinal dysraphism repair at Johns Hopkins Hospital. J Neurosurg Pediatr 7:47-51, 2011

35. Ruysch F: The Celebrated Dr. Frederic Ruysch's Practical Observations in Surgery and Midwifery. Now first Translated from the Latin into English, By a Physician. [Translation of Observationum anatomico-chirurgicarum centuria.] London: Printed for T. Osborne, 1751

36. Ruysch F: Observationum anatomico-chirurgicarum centuria. Amsterdam: Henricum \& Theodori Boom, 1691

37. Schama S: Rembrandt's Eyes. Toronto: Random House of Canada, 1999

38. Sidebottom E: Case of spina bifida treated by ligature. BMJ 2:345, 1869

39. Smith GK: The history of spina bifida, hydrocephalus, paraplegia, and incontinence. Pediatr Surg Int 17:424-432, 2001
40. Spiller W: Congenital and acquired enuresis from spinal lesion: a) myelodysplasia; b) stretching of the cauda equina.

Am J Med Sci 151:469-475, 1916

41. Steinbok P, Garton HJ, Gupta N: Occult tethered cord syndrome: a survey of practice patterns. J Neurosurg 104 (5 Suppl):309-313, 2006

42. Steinbok P, Kariyattil R, MacNeily AE: Comparison of section of filum terminale and non-neurosurgical management for urinary incontinence in patients with normal conus position and possible occult tethered cord syndrome. Neurosurgery 61:550-556, 2007

43. Tulp N: Observationum medicarum. Libri tres. Amsterdam: Apud Ludovicum Elzevirum, 1641

44. Virchow R: Ein fall von Hypertrichosis circumscripta mediana, kombiniert mit Spina bifida occulta. Ztschr f Ethnol 7:280-290, 1875

45. von Recklinghausen F: The classic: Studies on spina bifida. 1886. Clin Orthop Relat Res 469:1227-1229, 2011

46. Wilson WJ: Excision-cures of spina bifida. BMJ 2:522-523, 1869

47. Yamada S, Won DJ, Pezeshkpour G, Yamada BS, Yamada SM, Siddiqi J, et al: Pathophysiology of tethered cord syndrome and similar complex disorders. Neurosurg Focus 23(2):E6, 2007

48. Yamada S, Zinke DE, Sanders D: Pathophysiology of "tethered cord syndrome". J Neurosurg 54:494-503, 1981

49. Yashon D, Beatty RA: Tethering of the conus medullaris within the sacrum. J Neurol Neurosurg Psychiatry 29:244250,1966

\section{Disclosures}

The authors report no conflict of interest concerning the materials or methods used in this study or the findings specified in this paper.

\section{Author Contributions}

Conception and design: Preul, Safavi-Abbasi. Acquisition of data: Safavi-Abbasi, Archer, Wilson. Analysis and interpretation of data: Preul, Safavi-Abbasi, Mapstone, Spetzler. Drafting the article: Preul, Safavi-Abbasi, Theodore. Critically revising the article: Preul, Mapstone. Reviewed submitted version of manuscript: Preul. Administrative/technical/material support: Preul, Spetzler. Study supervision: Preul, Safavi-Abbasi.

\section{Correspondence}

Mark C. Preul, c/o Neuroscience Publications, Barrow Neurological Institute, St. Joseph's Hospital and Medical Center, 350 W. Thomas Rd., Phoenix, AZ 85013. email: neuropub@dignity health.org. 